\title{
MÉXICO: ENTRE LA VIOLENCIA Y LA CONSOLIDACIÓN DEL SISTEMA DE PARTIDOS
}

\author{
Mexico: Between Violence and the Consolidation \\ of the Party System
}

\author{
ESPERANZA PALMA*
}

Universidad Autónoma Metropolitana-Cuajimalpa

\begin{abstract}
RESUMEN
El año 2009 fue de particular relevancia para México. Los eventos más destacables fueron la agudización de la llamada narcoviolencia, generada por la lucha entre carteles de drogas en torno al control de territorios y entre éstos y el gobierno, la crisis económica y la realización de elecciones locales y de elecciones intermedias para renovar a los 500 diputados federales que conforman la Cámara. A la vez que se ha escalado la violencia en algunos estados del país, el sistema de partidos se ha consolidado; hay tres partidos que captan el $90 \%$ del voto y de los escaños en el Congreso y los procesos electorales durante este año se desarrollaron en un contexto de normalidad e institucionalidad muy diferente a la turbulencia de la elección presidencial de 2006. Sin duda, uno de los resultados más importantes de esta elección fue la recuperación del Partido Revolucionario Institucional (PRI) frente al retroceso del partido gobernante, el Partido Acción Nacional (PAN) y del Partido de la Revolución Democrática (PRD).
\end{abstract}

Palabras clave: México, narcoviolencia, elecciones intermedias, elecciones locales, partidos políticos.

\begin{abstract}
The year 2009 was particularly relevant for Mexico. The most outstanding events were increasing of the so called narco-violence, caused by inter-drug cartels war for controlling territory, and between the government and the cartels, economic crisis, and local and mid-term elections that elected 500 deputies of the legislature. While violence has escalated in some states, the party system has become a consolidated one; three parties size $90 \%$ of the national vote and of the seats in Congress and electoral processes took place in a normal and institutional manner, a very different situation from the 2006 turbulent presidential election. One of the most important outcomes of these elections was the electoral recovery of the Partido Revolucionario Institucional and the electoral erosion of the ruling party, Partido Acción Nacional, and The Partido de la Revolución Democrática.
\end{abstract}

Key words: Mexico, narco-violence, mid-term elections, local elections, political parties.

* Departamento de Ciencias Sociales, Universidad Autónoma Metropolitana-Cuajimalpa, Ciudad de México, eipc2000@yahoo.com 


\section{TEMAS SALIENTES DE LA REALIDAD NACIONAL Y SU IMPACTO POLÍTICO}

\section{i) La coyuntura social}

El problema más grave durante 2009 fue la violencia resultante de la lucha entre los carteles de drogas y entre estas organizaciones y el gobierno. La guerra contra el narcotráfico ha sido uno de los temas centrales en la agenda del Presidente Calderón desde que llegó a la presidencia en 2006 y decidió combatir frontalmente al narcotráfico con la intervención del Ejército. La violencia, no obstante, es el resultado de la lucha entre los cárteles por el control de territorios que se ha profundizado desde que el gobierno los ha confrontado.

El año 2009 es el que ha registrado un mayor número de ejecuciones en todo lo que va del sexenio. Según cifras oficiales, durante los tres años de gobierno de Calderón ha habido 22.700 muertos por ejecuciones entre cárteles y, en menor medida, por confrontaciones con las fuerzas armadas. En 2009 hubo 9.635 asesinados como resultado de ejecuciones entre los cárteles del Golfo/Zetas (grupos paramilitares que actúan como comandos de ajuste de cuentas) y "La familia" y el Cartel de Sinaloa (El Economista, 2010). La violencia está localizada en seis de los treinta y dos estados de la República: Chihuahua, que tuvo 3.637 ejecuciones en 2009, seguido de Guerrero (881), Sinaloa (814), Baja California (691), Michoacán (417) y Durango (341). ${ }^{1}$

La violencia entre los cárteles, los problemas enfrentados por el Estado para controlar el crimen organizado y la estrategia del gobierno de combate a estos grupos han abierto un debate público en torno a la situación del Estado mexicano y a la pertinencia y eficacia de la estrategia calderonista. Así, se ha vuelto popular entre la opinión pública y algunos círculos académicos la tesis de la ingobernabilidad del país y el Estado fallido queriendo enfatizar que el Estado está tomado por el crimen organizado y que su monopolio de la violencia ha sido puesto en cuestión mostrándose incapaz de proveer seguridad a sus ciudadanos. Además, la estrategia de Calderón ha resultado ser muy polémica y cuestionable, sobre todo porque no ha logrado reducir los índices de violencia, antes bien, tal como lo muestran las cifras, las ejecuciones van in crescendo. La violencia generada por el narco ha repercutido también en los niveles de participación electoral en casi todos los estados que son escenario de la lucha entre cárteles. En las elecciones intermedias celebradas en 2009, los estados que registraron las tasas más bajas de participación fueron justamente Baja California (31,24\% de participación), Chihuahua (32,60\%), Guerrero $(32,68 \%)$ y Michoacán (33,40\%).

Pero estos argumentos deben confrontarse con otros datos y tesis. Es de hacerse notar que para inicios de 2010, el 47\% de la población consideraba que los operativos establecidos por el gobierno federal para combatir al crimen organizado habían sido un éxito, frente al

Cálculos obtenidos de lo publicado por los diarios Milenio http:/ / (www.mileniodiario.com.mx) y El Universal (http:/ / eluniversal.com.mx) del año 2009. 
$36 \%$ que los considera un fracaso. Asimismo, el 74\% estaba de acuerdo en que el ejército participara en el combate a los cárteles. ${ }^{2}$

Para algunos observadores la tesis del Estado fallido es insostenible; a pesar de la violencia de los últimos años no se puede hablar de "narcopolítica"; los narcos no están detrás de las candidaturas ni las autoridades y tampoco han golpeado con actos terroristas a instituciones y personajes políticos como ha sucedido en otros países. Tampoco puede afirmarse que sea una guerra que está perdiendo el Estado. El narco es un enemigo dividido y la mayor parte de las bajas resultan de la autodestrucción de los propios cárteles que se profundiza cuando el Estado los confronta (Villalobos, 2010). A ello se agrega que la violencia está localizada, como ya se mencionó. Se ha encarcelado a jefes importantes del narco y existe debate público en torno a qué hacer y a las estrategias posibles.

Así, el efecto que ha tenido la lucha entre el narcotráfico en México no debe ni minimizarse ni exagerarse. Efectivamente, hay una crisis de seguridad que ha erosionado el espacio público y la calidad de vida de los mexicanos y el Estado enfrenta problemas serios para controlar al crimen organizado.

En otro ámbito de la vida social, destacó el decreto presidencial de extinción de la Compañía paraestatal "Luz y Fuerza del Centro" encargada de la generación y distribución de energía eléctrica a los estados del centro del país (Martínez, Castillo y Salgado, 2009). Dicha medida generó un conflicto relevante, que sigue en curso, con uno de los sindicatos más fuertes en México, el Sindicato Mexicano de Electricistas, SME, cuyos orígenes se remontan a 1914 cuando la empresa era privada y estaba en manos de extranjeros. El SME fue un sindicato poderoso que logró prestaciones para sus agremiados como pocos sindicatos en México. Desde hace años la Compañía de Luz y Fuerza del Centro estaba en la mira de gobiernos y empresarios debido a que operaba con números rojos y a su ineficiencia para suplir el servicio. La empresa representaba una carga de poco más de 40 mil millones de pesos anuales para el gobierno (poco más de 3 mil millones de dólares, al tipo de cambio de octubre de 2009). Contaba con alrededor de 44 mil empleados y 23 mil jubilados. El conflicto tuvo inicio cuando la Secretaría del Trabajo y Previsión Social se negó al trámite de "toma de nota" 3 del ganador de la elección interna del sindicato para renovar a su comité ejecutivo y secretario argumentando que, como denunciaron algunos de sus miembros y, en particular, la planilla perdedora, había irregularidades en la elección (Sánchez, 2009). El gobierno aprovechó el conflicto dentro del sindicato declarando a la empresa en quiebra por decreto el 11 de octubre de 2009. Se decidió que su servicio sería absorbido por la otra paraestatal, la Comisión Federal de Electricidad. Alrededor de 40 mil trabajadores fueron despedidos vía liquidación.

A partir de ese momento el SME ha llevado a cabo acciones para oponerse a la medida del gobierno. Inicialmente se amparó frente a la Junta Federal de Conciliación y Arbitraje,

Datos obtenidos de México Unido contra la delincuencia. http:/ / www.mucd.org.mx (Consulta: 10-3-2010). De acuerdo a los artículos 365, 371 y 377 de la ley federal del trabajo, la Secretaría del Trabajo tiene la facultad de cotejar la información que presenten los sindicatos para el cambio de su directiva a fin de verificar si el procedimiento se apegó a los estatutos y refleja la libre voluntad de sus agremiados. La toma de nota es una suerte de certificación (Secretaría del Trabajo y Previsión Social, 2009). 
pero la controversia fue negada por improcedente para revertir el decreto de extinción. Ante ello el sindicato convocó a una huelga nacional, llamado que no prosperó (Roldán, 2010), y algunos de sus trabajadores se pusieron en huelga de hambre (Fernández, 2010). Se formó una comisión de notables, que pudiera mediar entre las partes. Hasta mediados de 2010 el conflicto seguía en pie.

La medida tomada por el gobierno ha abierto uno de los grandes temas divisorios de los partidos y la opinión pública en México en torno al control estatal de sectores estratégicos de la economía. En 2008 la polémica surgió a propósito de la propuesta de reforma presidencial de la paraestatal "Petróleos Mexicanos", para permitir la inversión privada en algunas áreas de la producción del petróleo tales como la exploración. No sólo las élites partidistas sino también la población se dividieron frente a la propuesta de permitir la inversión privada en este sector clave de la economía.

\section{ii) Coyuntura económica}

A la crisis de seguridad se sumó la crisis económica. En 2009, 82\% de los ciudadanos percibió que la situación económica había empeorado en relación al año anterior (Consulta Mitofsky, 2010). La crisis era percibida como el principal problema del país, antes que el narcotráfico o la inseguridad. De acuerdo a Consulta Mitoksky, el 37,7\% percibió que la crisis era el principal problema del país, el 16,9\% dijo ser la inseguridad, el 16,3\% el desempleo, $8 \%$ la pobreza, 4,7\% el narcotráfico y 4,3\% la corrupción.

En la Tabla 1 se muestran algunos indicadores económicos para este año.

Tabla 1: Indicadores económicos, 2009

\begin{tabular}{lcccc}
\hline \multicolumn{1}{c}{ Indicadores } & 2008 & $\begin{array}{c}2009 \\
\text { Trimestre I }\end{array}$ & $\begin{array}{c}2009 \\
\text { Trimestre II }\end{array}$ & $\begin{array}{c}2009 \\
\text { Trimestre III }\end{array}$ \\
\hline PIB & 1.088 & 776,9 & 854,0 & 899,2 \\
Inflación & 6,53 & 6,0 & 5,7 & 4,9 \\
Exportaciones & 291,8 & 50,0 & 54,3 & 58,2 \\
Importaciones & 308,6 & 52,0 & 53,6 & 61,3 \\
Inversión extranjera & 22,5 & 5,6 & 4,8 & $-0,6$ \\
\hline
\end{tabular}

Fuente: Banco de México. www.banxico.org.mx/.

La crisis ha sido severa en México aunque hacia el último trimestre de 2009 hubo una ligera recuperación y mejoría en indicadores tales como la inflación y el producto interno bruto. La inversión extranjera, no obstante, ha ido en declive, probablemente también debido a la crisis de seguridad que hace de México un país incierto para la inversión.

El gobierno mexicano ha sido criticado por la forma de enfrentar la crisis que, al parecer, ha sido más severa en México que en otros países latinoamericanos. Por ejemplo, el premio Nobel de Economía 2001 Joseph Stiglitz desató una polémica al destacar que 
México había enfrentado mal la crisis y que los principales problemas habían sido la lentitud con la que reaccionó el gobierno calderonista y el aumento en los impuestos. Según la visión del premio Nobel, el gobierno del Presidente Calderón se preocupó por encontrar la forma de obtener recursos para el erario pero descuidando la situación de pobreza y de desempleo por la que atravesaba el país previo a la crisis mundial. La economía en México lejos de estimularse se contrajo con el incremento en los impuestos y con el constante aumento de los energéticos (Lombera, 2009).

\section{iii) Coyuntura política: elecciones nacionales y subnacionales}

La coyuntura política en 2009 estuvo marcada por la realización de las elecciones intermedias para renovar la Cámara de Diputados y de procesos electorales locales. Uno de los resultados más importantes de estos procesos fue la recuperación del Partido Revolucionario Institucional en varios estados en donde gobernaba el PAN y su posicionamiento como primera fuerza parlamentaria en la Cámara de Diputados. El regreso del otrora partido hegemónico ha sido objeto de análisis y debate académico y político. De particular importancia es el impacto que ha tenido la recuperación priísta en las estrategias electorales del PAN y el PRD a nivel local. En 2010 estos partidos decidieron establecer alianzas en varias elecciones locales para renovar la gubernatura con el objetivo de derrotar al PRI en sus estados duros, como Hidalgo y Oaxaca, en los cuales no ha perdido su posición dominante (nunca ha perdido las gubernaturas ni el control mayoritario de los congresos de los estados). Así, el eje fundamental de la plataforma de estas coaliciones locales es la transición democrática (Guerrero, 2010). El objetivo del PAN y el PRD es entrar a ese mercado electoral local y generar un impacto en el electorado con miras a la elección presidencial de 2012 para restarle posibilidades al PRI de regresar a la presidencia.

También cabe señalar que las elecciones tuvieron lugar en un contexto anticlimático, en medio de una fuerte crítica pública a los partidos. El antipartidismo se expresó en el llamado "Movimiento por el voto nulo", en el cual participaron algunos líderes de opinión, organizaciones sociales y ex militantes y líderes de partidos políticos. Entre los temas y propuestas de este pseudomovimiento se encontraban la democracia participativa, la reducción del financiamiento a los partidos y la incorporación de las candidaturas independientes, no reconocidas hasta ahora por la ley electoral (Palma, 2009).

Lo anterior, no obstante, no se tradujo en un aumento del abstencionismo.

A continuación se muestran datos de los resultados de las elecciones nacionales y locales.

\section{ELECCIONES NACIONALES Y SUBNACIONALES}

Como se muestra en la Tabla 2, el PAN, el partido gobernante, perdió su condición de primera fuerza parlamentaria frente al PRI en la elección intermedia: del $41 \%$ de 
curules que controlaba en la legislatura anterior ahora contará con el 29\%. A juzgar por la legislatura anterior, no se prevé falta de cooperación entre el Presidente y el Congreso en tanto el PRI ha sido uno de los soportes del PAN para la aprobación de leyes.

Por su parte, el PRD pasó a ser la tercera fuerza electoral. En tan sólo tres años, su fuerza se redujo drásticamente en parte debido a sus agudas divisiones internas entre la corriente "Nueva Izquierda" e "Izquierda Unida"; la primera de corte socialdemócrata y la segunda populista y más radical. En 2008 la pugna entre los bloques se dio en torno al control de la dirección del partido que terminó en una elección interna impugnada.

El PRI y los partidos menores de izquierda como el PT, otrora aliado de este partido, lograron capitalizar esta división. Si analizamos los resultados por estado se puede observar que la fuerza perredista se reduce a cuatro estados, el Distrito Federal, Michoacán, Baja California y Zacatecas, estados en los que gobierna. El PRI, en cambio, obtuvo mayoría en 20 estados de 32, muchos de ellos panistas, en contraste con los siete en los que había ganado en 2006. El PAN ganó en ocho en esta elección (IFE, 2010).

Tabla 2: Número y porcentaje de curules por partido en las LX y LXI legislaturas

\begin{tabular}{lccccccccc}
\hline \multicolumn{1}{c}{ Legislaturas } & PAN & PRI & PRD & PVEM & CONV. & PT & PANAL & PSD & TOTAL \\
\hline Legislatura & 206 & 106 & 127 & 17 & 18 & 11 & 9 & 5 & 500 \\
LX & $41 \%$ & $21 \%$ & $25 \%$ & $3 \%$ & $3,6 \%$ & $2,2 \%$ & $1,8 \%$ & $1 \%$ & curules \\
2006-2009 & & & & & & & & & $100 \%$ \\
Legislatura & 143 & 237 & 71 & 21 & 6 & 13 & 9 & - & 500 \\
LXI & $28,6 \%$ & $47,4 \%$ & $14,2 \%$ & 4,2 & $1,2 \%$ & $2,6 \%$ & $1,8 \%$ & & $100 \%$ \\
2009-2012 & & & & & & & & & \\
\hline
\end{tabular}

Fuente: Elaboración propia con datos de la Cámara de Diputados (www.diputados.gob.mx).

Notas: el PSD perdió el registro en la elección de 2009. El requisito para obtener y mantener el registro es de $2 \%$ de la votación nacional.

De los 500 diputados, 300 se eligen por el principio de mayoría relativa y 200 por representación proporcional elegidos en cinco circunscripciones en listas cerradas.

Siglas:

PAN: Partido Acción Nacional

PRI: Partido Revolucionario Institucional

PRD: Partido de la Revolución Democrática

PVEM: Partido Verde Ecologista de México

Conv: Convergencia

PT: Partido del Trabajo

PANAL: Partido Nueva Alianza

PSD: Partido Socialdemócrata

Las diferencias de porcentaje de votos obtenidos por los partidos de 2006 a 2009 se muestran en la Tabla 3: 
Tabla 3: Volatilidad

\begin{tabular}{lccccccccccc}
\hline $\begin{array}{c}\text { Elección } \\
\text { para } \\
\text { Diputados }\end{array}$ & PAN & PRI & PRD & PVEM & $\begin{array}{c}\text { CON- } \\
\text { VERG. }\end{array}$ & PT & PANAL & PSD $\begin{array}{c}\text { Indepen- } \\
\text { dientes }\end{array}$ & Total \\
\hline 2006 & 33,41 & 25,58 & 22,99 & 2,6 & 3,5 & 2,5 & 4,54 & 2,05 & 0,31 & 97,17 & Índice \\
de & \\
2009 & 28,01 & 36,94 & 12,19 & 6,71 & 2,46 & 3,66 & 3,42 & 1,03 & 0,16 & 94,58 & $\begin{array}{c}\text { dedersen } \\
21,5 \%\end{array}$ \\
Ganancia & $-5,4$ & 11,36 & $-10,8$ & 4,11 & $-1,04$ & 1,16 & $-1,12$ & $-1,02$ & $-0,15$ & 21,48 & 21,5 \\
o pérdida & & & & & & & & & & & \\
\hline
\end{tabular}

Nota: El total no suma $100 \%$ porque no se incluyeron los votos nulos.

A pesar de ser una elección intermedia y del ambiente antipartidista que existía en el ánimo del público, la participación aumentó 3\% en este año en relación a la elección intermedia de 2003.

Gráfico 1: Porcentajes de participación electoral, 1997-2009

(Participación calculada sobre la base del padrón)

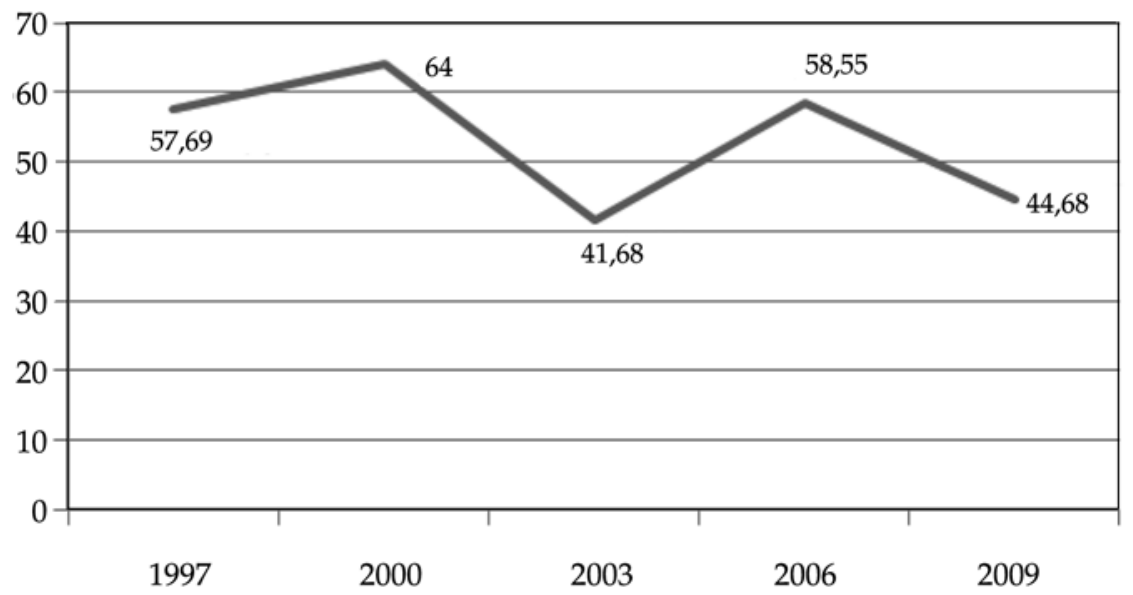

Fuente: Instituto Federal Electoral (ife.org.mx).

En esta elección intermedia hubo muy pocos avances en materia de representación de género. A pesar de que la ley electoral obliga a los partidos a cumplir con una proporción de 60/40 por ciento de candidaturas por género, deja también la puerta abierta al incumplimiento de la cuota al permitir que no sea oligatoria en caso de que los partidos realicen elecciones democráticas. Por ello, el colocar a mujeres en los primeros sitios de las listas de representación proporcional es crucial para que puedan entrar a la Cámara. 
También resalta que los partidos colocan candidaturas simbólicas al darles a las mujeres la suplencia en lugar de la titularidad en las candidaturas de mayoría, lo cual cuenta para el cumplimiento de la cuota.

Así, el PRD colocó únicamente a 87 candidatas mujeres por mayoría, frente a 107 del PAN y 49 del PRI. Sin embargo, por la vía plurinominal, propuso a 104 mujeres, frente a 100 del PRI y 95 del PAN, lo cual es relevante porque la vía plurinominal puede garantizar la entrada en la Cámara de Diputados si se ocupa uno de los primeros lugares (IFE, 2009).

El resultado fue que el porcentaje de mujeres legisladoras quedara muy por debajo del ideal de paridad de género. Comparando con la composición de la Cámara anterior (2006-2009) en donde había 124 mujeres de 500, en la legislatura instalada en 2009 sólo aumentó a 131.

Tabla 4: Composición de la Cámara de Diputados por género, por partido, 2009-2012

\begin{tabular}{lrlrlrl}
\hline $\begin{array}{c}\text { Grupo } \\
\text { Parlamentario }\end{array}$ & Hombres & $\%$ & Mujeres & $\%$ & Total & $\%$ \\
\hline PAN & 140 & 68 & 66 & 32 & 206 & 100 \\
PRD & 98 & 78,4 & 27 & 21,6 & 125 & 100 \\
PRI & 87 & 82,1 & 19 & 17,9 & 106 & 100 \\
CONV & 15 & 83,3 & 3 & 16,7 & 18 & 100 \\
PVEM & 12 & 70,6 & 5 & 29,4 & 17 & 100 \\
PT & 8 & 72,7 & 3 & 27,3 & 11 & 100 \\
NA & 4 & 44,4 & 5 & 55,6 & 9 & 100 \\
ALT & 3 & 60 & 2 & 40 & 5 & 100 \\
IND & 2 & 66,7 & 1 & 33,3 & 3 & 100 \\
Total & 369 & 73,8 & 131 & 26,2 & 500 & 100 \\
\hline
\end{tabular}

Fuente: Cámara de Diputados en www.diputados.gob.mx.

El año de 2009 fue muy intenso electoralmente. No sólo se renovó la Cámara de Diputados sino que también tuvieron lugar elecciones estatales en 14 estados: se renovaron seis gubernaturas, 208 diputaciones locales y 620 alcaldías.

En la Tabla 5 se muestran los resultados para las elecciones a gobernador. Si bien el PRI perdió una gubernatura, Sonora, le arrebató al PAN dos, San Luis Potosí y Querétaro, que habían sido bastiones panistas desde la democratización. El PRI conservó además Colima y Campeche. Resalta la marginalidad del PRD en al menos tres de los estados; en dos de ellos, Querétaro y Campeche, obtuvo menos del 2\% de la votación. Las explicaciones de esta recuperación del PRI incluyen su trabajo territorial en los estados opositores, el cuidado de su selección de candidatos, el desgaste del PAN como partido gobernante y la crisis interna del PRD. 
Tabla 5: Resultados en las elecciones para gobernador, 2009

\begin{tabular}{llcr}
\hline \multicolumn{1}{c}{ Estado } & Partido & Porcentaje en 2003 & Porcentaje en 2009 \\
\hline San Luis Potosí & PRI & 37,6 & 45,4 \\
& PAN & 42,8 & 41,9 \\
\multirow{5}{*}{ Sonora } & PRD & 15 & 8,6 \\
& PRI & 46,4 & 43,6 \\
\multirow{5}{*}{ Nuevo León } & PAN & 45,4 & 47,6 \\
& PRD & 6,4 & 3,9 \\
\multirow{5}{*}{ Colima } & PRI & 56,7 & 48,8 \\
& PAN & 33,8 & 43,6 \\
& PRD & 1 & 3,4 \\
Campeche & PRI & 51,6 & 50,9 \\
& PAN-PRD & 47,8 & 44,5 \\
\multirow{5}{*}{ Querétaro } & PRD & - & 2,1 \\
& PRI & 40,7 & 51,2 \\
& PAN & 38,8 & 43,1 \\
& PRD & 1,6 & 0,8 \\
& PRI & 42 & 47,4 \\
& PAN & 45,7 & 42,2 \\
\hline
\end{tabular}

Fuentes: Elaboración propia con datos del Instituto Federal Electoral www.ife.org.mx; Sistema Electoral Mexicano www.imocorp.com.mx; Institutos y Consejos Electorales Estatales.

Los resultados del número de distritos locales y alcaldías ganados por partido también muestran claramente la recuperación del PRI y el retroceso relevante de los otros dos partidos.

Tabla 6: Resultados para diputados locales y alcaldías, 2009

\begin{tabular}{|c|c|c|c|c|}
\hline \multirow{2}{*}{ Partido } & \multicolumn{2}{|c|}{ Distritos ganados } & \multicolumn{2}{|c|}{ Alcaldías ganadas } \\
\hline & 2006 & 2009 & 2006 & 2009 \\
\hline PRI & 82 & 150 & 261 & 319 \\
\hline PAN & 123 & 91 & 236 & 216 \\
\hline PRD & 75 & 38 & 100 & 49 \\
\hline PT & 0 & 1 & 5 & 10 \\
\hline $\mathrm{PCP}^{4}$ & & & 3 & 3 \\
\hline PANAL & & & 1 & 1 \\
\hline PVEM & & & 9 & 10 \\
\hline CONVERGENCIA & & & 4 & 10 \\
\hline PUPC $^{5}$ & & & 1 & \\
\hline PSD & & & & 2 \\
\hline Total & 280 & 280 & 620 & 620 \\
\hline
\end{tabular}

Fuentes: Elaboración propia con datos del Instituto Federal Electoral www.ife.org.mx; Sistema Electoral Mexicano www.imocorp.com.mx; Institutos y Consejos Electorales Estatales.

Total de distritos a disputarse: 280, total de alcaldías: 620 . 
Como se mencionó anteriormente, la recuperación del PRI en estas elecciones llevó a la formación de coaliciones opositoras PAN-PRD para algunas elecciones locales de 2010 en estados en donde el PRI sigue siendo predominante. La formación de estas coaliciones no ha estado exenta de conflictos internos en los partidos. Probablemente, uno de los mayores problemas fue el que ocurrió entre el Secretario de Gobernación, Gómez Mont, y su partido, el PAN, quien se había comprometido con el PRI a no establecer coaliciones con el PRD a cambio de la aprobación de la reforma fiscal. El Secretario renunció al PAN.

Por otra parte, como se verá más adelante, algunas de las demandas del llamado "Movimiento anulacionista" fueron incorporadas a la propuesta de reforma política enviada por el Ejecutivo al Senado en diciembre de 2009, tales como las candidaturas independientes y la reducción del presupuesto a los partidos.

\section{PODER EJECUTIVO}

El año 2009 no ha sido fácil para el Presidente Calderón debido a la crisis de seguridad y a la crisis económica. Su aprobación ha ido en declive: en enero de este año 66\% aprobaba su labor, mientras que en diciembre cayó a 55\% (Mitofsky, 2010).

En México, es facultad exclusiva del Presidente nombrar a los miembros de su gabinete. Únicamente en los casos del Procurador General de la República, Jefes del Ejército, la Armada y la Fuerza Aérea, el Senado tiene que ratificar los nombramientos.

La Tabla que se presenta a continuación muestra la composición del gabinete de Felipe Calderón. No existe ninguna coalición ejecutiva. De un total de 19 secretarías y una procuraduría, ocho están en manos de panistas y doce secretarios no tienen filiación partidista. Sólo cinco son mujeres. Hubo cambios de 12 de ellos entre 2008 y 2009, en parte debido a que algunos se fueron como candidatos para diputados en 2009. Si bien sólo menos de la mitad de las secretarías está en manos de panistas, Calderón, a diferencia del Presidente Fox, ha proyectado una imagen de un gobierno de tinte panista bajo su dirección.

Tabla 7: Gabinete Presidencial 2009

\begin{tabular}{lccc}
\hline & $\begin{array}{c}\text { Titulares } \\
\text { panistas } \\
\text { (militantes) }\end{array}$ & $\begin{array}{c}\text { Titulares } \\
\text { Independientes } \\
\text { del PAN }\end{array}$ & $\begin{array}{c}\text { Total de } \\
\text { mujeres } \\
\text { titulares }\end{array}$ \\
\hline $\begin{array}{l}\text { Gabinete Económico: } \\
\text { S.H.C.P. SENER, SE, SCT, STPS, }\end{array}$ & 5 & 1 & 2 \\
SECTUR & & & \\
\hline
\end{tabular}

6 Aunque no militan en el PAN han tenido relación con el gobierno foxista. Ninguno está ligado al PRI o al PRD. El único que quedaba era Guillermo Ortiz del Banxico pero fue sustituido por Agustín Carstens. 


\begin{tabular}{lccc}
\hline & $\begin{array}{c}\text { Titulares } \\
\text { panistas } \\
\text { (militantes) }\end{array}$ & $\begin{array}{c}\text { Titulares } \\
\text { Independientes } \\
\text { del PAN }\end{array}$ & $\begin{array}{c}\text { Total de } \\
\text { mujeres } \\
\text { titulares }\end{array}$ \\
\hline $\begin{array}{l}\text { Gabinete Social: } \\
\text { SEDESOL, SENARNAT, }\end{array}$ & 2 & 4 & 1 \\
SAGARPA, SEP, SALUD, SRA & 0 & 4 & 0 \\
$\begin{array}{l}\text { Gabinete de Seguridad: } \\
\text { SSP } \\
\text { SEDENA }\end{array}$ & & & \\
$\begin{array}{l}\text { SEMAR } \\
\text { PGR }\end{array}$ & & & 2 \\
$\begin{array}{l}\text { Gabinete Político: } \\
\text { SEGOB } \\
\text { SRE } \\
\text { Función Pública }\end{array}$ & 1 & 3 & \\
Oficina de la Presidencia & & & \\
Total & & & 5 \\
\hline
\end{tabular}

Fuente: Elaboración propia con información de Presidencia de la República www.presidencia. gob.mx

En la siguiente Tabla 8 se presentan algunos datos biográficos de los miembros del gabinete.

Tabla 8: Datos biográficos de los miembros del gabinete 2009

\begin{tabular}{|c|c|c|c|}
\hline Puesto & Titular & $\begin{array}{c}\text { Año de } \\
\text { nacimiento }\end{array}$ & Estudios y filiación \\
\hline $\begin{array}{l}\text { Secretaría de } \\
\text { Gobernación }\end{array}$ & $\begin{array}{l}\text { Fernando Francisco } \\
\text { Gómez-Mont Urueta }\end{array}$ & 1963 & $\begin{array}{l}\text { Licenciado en Derecho por la Escuela Libre } \\
\text { de Derecho. } \\
\text { Panista }\end{array}$ \\
\hline $\begin{array}{l}\text { Secretaría de } \\
\text { Relaciones } \\
\text { Exteriores }\end{array}$ & $\begin{array}{l}\text { Patricia Espinosa } \\
\text { Cantellano }\end{array}$ & 1958 & $\begin{array}{l}\text { Licenciada en Relaciones Internacionales } \\
\text { por El Colegio de México y estudios de } \\
\text { Posgrado en Derecho Internacional por el } \\
\text { Instituto Universitario de Altos Estudios } \\
\text { Internacionales en Ginebra, Suiza. } \\
\text { Técnica }\end{array}$ \\
\hline $\begin{array}{l}\text { Secretaría de } \\
\text { Hacienda y } \\
\text { Crédito Público }\end{array}$ & Ernesto Cordero Arroyo & 1968 & $\begin{array}{l}\text { Licenciado en Actuaría y Maestro en } \\
\text { Economía por el ITAM. Es Maestro en } \\
\text { Economía. } \\
\text { Panista }\end{array}$ \\
\hline $\begin{array}{l}\text { Secretaría } \\
\text { de la } \\
\text { Defensa } \\
\text { Nacional }\end{array}$ & $\begin{array}{l}\text { Gral. Guillermo Galván } \\
\text { Galván }\end{array}$ & 1943 & $\begin{array}{l}\text { Licenciado en Administración militar y } \\
\text { Maestro en Seguridad y Defensa Nacional } \\
\text { por el Colegio de la Defensa Nacional. } \\
\text { Militar }\end{array}$ \\
\hline
\end{tabular}




\begin{tabular}{|c|c|c|c|}
\hline Puesto & Titular & $\begin{array}{l}\text { Año de } \\
\text { nacimiento }\end{array}$ & Estudios y filiación \\
\hline $\begin{array}{l}\text { Secretaría de } \\
\text { Marina }\end{array}$ & $\begin{array}{l}\text { Almir. Mariano Francisco } \\
\text { Saynez Mendoza }\end{array}$ & 1942 & $\begin{array}{l}\text { Ingeniero geógrafo y estudios de mando } \\
\text { naval, comportamiento humano en las } \\
\text { organizaciones, de mando superior y } \\
\text { seguridad nacional por el Heroico Colegio } \\
\text { Militar y Centros de Estudios Superiores } \\
\text { Navales de México. } \\
\text { Militar }\end{array}$ \\
\hline $\begin{array}{l}\text { Secretaría de } \\
\text { Economía }\end{array}$ & Gerardo Ruiz Mateos & 1965 & $\begin{array}{l}\text { Ingeniero Industrial por el Instituto } \\
\text { Tecnológico de Estudios Superiores de } \\
\text { Monterrey. } \\
\text { Panista }\end{array}$ \\
\hline $\begin{array}{l}\text { Secretaría de } \\
\text { Desarrollo } \\
\text { Social }\end{array}$ & Heriberto Félix Guerra & 1962 & $\begin{array}{l}\text { Licenciado en Economía por el Instituto } \\
\text { Tecnológico y de Estudios Superiores de } \\
\text { Monterrey. } \\
\text { Técnico }\end{array}$ \\
\hline $\begin{array}{l}\text { Procuraduría } \\
\text { General de la } \\
\text { República }\end{array}$ & Arturo Chávez Chávez & 1960 & $\begin{array}{l}\text { Licenciado en Derecho en el Instituto } \\
\text { Tecnológico y de Estudios Superiores de } \\
\text { Monterrey. } \\
\text { Técnico. Experiencia en procuración de } \\
\text { justicia }\end{array}$ \\
\hline $\begin{array}{l}\text { Secretaría de } \\
\text { Seguridad } \\
\text { Pública }\end{array}$ & Genaro García Luna & 1968 & $\begin{array}{l}\text { Ingeniero mecánico por la Universidad } \\
\text { Autónoma Metropolitana. } \\
\text { Técnico }\end{array}$ \\
\hline $\begin{array}{l}\text { Secretaría de la } \\
\text { Función Pública }\end{array}$ & Salvador Vega Casillas & 1961 & $\begin{array}{l}\text { Contador público. Realizó estudios de } \\
\text { posgrado en Dirección y Gestión Pública } \\
\text { Local por la Universidad Carlos III de } \\
\text { Madrid. } \\
\text { Panista }\end{array}$ \\
\hline $\begin{array}{l}\text { Secretaría de } \\
\text { Comunicaciones } \\
\text { y Transportes }\end{array}$ & $\begin{array}{l}\text { Juan Francisco Molinar } \\
\text { Horcasitas }\end{array}$ & 1955 & $\begin{array}{l}\text { Estudios de licenciatura y posgrado en } \\
\text { Ciencia Política por El Colegio de México. } \\
\text { Panista }\end{array}$ \\
\hline $\begin{array}{l}\text { Secretaría del } \\
\text { Trabajo y } \\
\text { Previsión Social }\end{array}$ & Javier Lozano Alarcón & 1962 & $\begin{array}{l}\text { Abogado por la Escuela Libre de Derecho. } \\
\text { Técnico }\end{array}$ \\
\hline $\begin{array}{l}\text { Secretaría } \\
\text { del Medio } \\
\text { Ambiente y } \\
\text { Recursos Naturales }\end{array}$ & Juan Rafael Elvira Quesada & 1958 & $\begin{array}{l}\text { Ingeniero Agrícola por la UNAM. } \\
\text { Técnico }\end{array}$ \\
\hline $\begin{array}{l}\text { Secretaría de } \\
\text { Energía }\end{array}$ & Georgina Kessel Martínez & 1956 & $\begin{array}{l}\text { Licenciatura y Doctorado en economía por } \\
\text { Columbia University. } \\
\text { Técnica }\end{array}$ \\
\hline $\begin{array}{l}\text { Secretaría de } \\
\text { Agricultura, } \\
\text { Ganadería, } \\
\text { Desarrollo Rural, } \\
\text { Pesca y } \\
\text { Alimentación }\end{array}$ & $\begin{array}{l}\text { Francisco Javier Mayorga } \\
\text { Castañeda }\end{array}$ & 1951 & $\begin{array}{l}\text { Licenciado en Economía y maestro en } \\
\text { Administración de Empresas por el Instituto } \\
\text { Tecnológico Autónomo de México. } \\
\text { Técnico }\end{array}$ \\
\hline
\end{tabular}




\begin{tabular}{|c|c|c|c|}
\hline Puesto & Titular & $\begin{array}{c}\text { Año de } \\
\text { nacimiento }\end{array}$ & Estudios y filiación \\
\hline $\begin{array}{l}\text { Secretaría de } \\
\text { Educación } \\
\text { Pública }\end{array}$ & Alonso Lujambio Irazábal & 1962 & $\begin{array}{l}\text { Estudios en Ciencias Políticas por la } \\
\text { Universidad de Yale. } \\
\text { Académico/Cercano a Calderón }\end{array}$ \\
\hline $\begin{array}{l}\text { Secretaría de } \\
\text { Salud }\end{array}$ & $\begin{array}{l}\text { José Ángel Córdova } \\
\text { Villalobos }\end{array}$ & 1953 & $\begin{array}{l}\text { Médico Cirujano y Maestro en } \\
\text { Administración Pública por la Universidad } \\
\text { de Guanajuato. } \\
\text { Panista }\end{array}$ \\
\hline $\begin{array}{l}\text { Secretaría de } \\
\text { Turismo }\end{array}$ & Gloria Guevara Manzo & 1967 & $\begin{array}{l}\text { Licenciada en Informática y Maestra } \\
\text { en Administración con especialidad en } \\
\text { Mercadotecnia por la Universidad Anáhuac. } \\
\text { Técnica }\end{array}$ \\
\hline $\begin{array}{l}\text { Secretaría de la } \\
\text { Reforma } \\
\text { Agraria }\end{array}$ & Abelardo Escobar Prieto & 1946 & $\begin{array}{l}\text { Agrónomo y Maestro en Ciencias por } \\
\text { New Mexico State University. } \\
\text { Técnico }\end{array}$ \\
\hline $\begin{array}{l}\text { Oficina de la } \\
\text { Presidencia } \\
\text { de la República }\end{array}$ & Patricia Flores Elizondo & 1968 & $\begin{array}{l}\text { Licenciada en Ciencias de la Comunicación } \\
\text { e Información por la Universidad de } \\
\text { Monterrey. } \\
\text { Panista }\end{array}$ \\
\hline
\end{tabular}

Fuentes: Elaboración propia con datos Presidencia de la República: http:/ /www.presidencia.gob. $\mathrm{mx}$ /index.php?DNA=33 y Magar y Romero (2008).

\section{PODER LEGISLATIVO}

\section{i) Los partidos en el Congreso: orientaciones ideológicas y organización}

El Congreso está compuesto por tres partidos mayores que abarcan el espectro ideológico de izquierda-derecha el PRI, el PAN y el PRD y tres menores: el Verde Ecologista, Convergencia y el Partido del Trabajo. Recientemente, el Verde ha hecho alianzas electorales con el PRI y Convergencia y el PT con el PRD, en algunos procesos electorales.

Desde que perdió la presidencia, el PRI ha caído en una ambigüedad ideológica. Formalmente es socialdemócrata pero sus posturas frente a temas sociales son sumamente conservadoras, como su posición frente al aborto, que lo colocan a la derecha del espectro político junto al PAN. En 2009 se corroboró su conservadurismo al ser el principal promotor de leyes de penalización del aborto en los estados en los cuales contaba con mayoría en los congresos locales. Con el apoyo del PAN logró aprobar estas medidas en la mitad de los 32 estados de la república, lo que amenazaba con convertirse en ley federal. De hecho, fue por su posición frente a este tema que en 2009 fue expulsado de la Internacional Socialdemócrata. Asimismo, algunos estudios muestran que el electorado priísta es más conservador que el del PAN en relación a temas tales como el aborto, el divorcio, la homosexualidad y la libertad sexual (Magaloni y Moreno, 2010). 
En materia de político-económica, el PRI se divide entre posturas neoliberales y otras más nacionalistas cercanas al PRD.

El PAN es un partido cercano a la democracia cristiana (Magaloni y Moreno, 2010) que en lo económico defiende un proyecto neoliberal que enfatiza la competencia, la propiedad privada de empresas y la necesidad de crear incentivos para el esfuerzo individual.

Por su parte, el PRD está dividido entre una izquierda nacionalista, social, tendiente a apoyar fuertes liderazgos y basada en organizaciones sociales, y otra de corte socialdemócrata comprometida con la institucionalidad y promotora de una agenda de corte postmaterialista.

En cuanto a los partidos menores, el PVEM tiene el curioso rasgo de no contar con una agenda ecologista; está a favor de la pena de muerte, no incluye demandas serias en torno a la protección de la ecología o el desarrollo sustentable y ha sido más bien un partido de familias. No obstante, ha logrado mantener el registro y permanecer como una fuerza parlamentaria debido a sus alianzas electorales con el PRI en los últimos años. De igual manera, Convergencia y el Partido del Trabajo han sobrevivido en buena medida gracias a sus coaliciones con el PRD. En 2006 armaron con el PRD la "Coalición por el Bien de Todos" y apoyaron la candidatura de López Obrador. En 2009, la relación de estos partidos con el PRD fue conflictiva; apoyaron candidaturas comunes en algunos estados y en otros no, debido a la confrontación con la dirección del PRD en este momento en manos de la fracción socialdemócrata.

\section{ii) Productividad legislativa}

Si tomamos el número de iniciativas que quedaron pendientes de ser aprobadas en la LX legislatura, la productividad legislativa ha sido baja en los tres primeros años del gobierno de Felipe Calderón. Sin embargo, cabe destacar que de las 37 iniciativas enviadas por el Presidente, 32 han sido aprobadas (ver Tabla 9). En comparación con las iniciativas presentadas por el PRD y el PRI, las del PAN tuvieron un mayor grado de aprobación, en tanto fue en esta legislatura, que llegó a su fin en 2009, el grupo parlamentario más grande.

Estudios de esta legislatura muestran que a pesar de que hay una tendencia a lo largo de las últimas legislaturas a un déficit en el grado de aprobación y dictaminación de iniciativas, la LX legislatura se caracterizó por aprobar reformas estructurales y por los acuerdos entre las tres principales fuerzas políticas (Delgado, 2008). En 2009, las iniciativas más importantes en ser aprobadas fueron la reforma fiscal (que permitió aumentar el impuesto al valor agregado al 16\% y el impuesto sobre la renta al 30\%) y la ley de regulación del uso de la fuerza por los integrantes de las instituciones de seguridad pública, entre otros (Cámara de Diputados, www.diputados.gob.mx). Los acuerdos entre el PAN y el PRI fueron muy importantes en esta legislatura, así como la cooperación con el Ejecutivo. 
Tabla 9: Iniciativas de ley LX legislatura (2006-2009)

\begin{tabular}{|c|c|c|c|c|c|c|c|}
\hline \multirow[t]{2}{*}{ Origen } & $1^{\text {er. año }}$ & $2^{\circ}$ año & $3^{\text {er. }}$ año & $\begin{array}{c}\text { Total } \\
\text { Presen- } \\
\text { tadas } \\
\text { en los } \\
\text { tres años }\end{array}$ & \multirow[t]{2}{*}{$\begin{array}{l}\text { Apro- } \\
\text { badas }\end{array}$} & \multirow[t]{2}{*}{$\begin{array}{l}\text { Dese- } \\
\text { chadas }\end{array}$} & \multirow[t]{2}{*}{$\begin{array}{c}\text { Pen- } \\
\text { dientes }\end{array}$} \\
\hline & 2007 & 2008 & 2009 & 2007-2009 & & & \\
\hline Poder Ejecutivo Federal & 14 & 9 & 14 & 37 & 32 & 0 & 5 \\
\hline Senadores de la República & 43 & 44 & 41 & 128 & 26 & 2 & 100 \\
\hline Legislaturas de los Estados & 25 & 13 & 45 & 83 & 10 & 6 & 67 \\
\hline Asamblea Legislativa del D.F. & 2 & 2 & 6 & 10 & 0 & 1 & 9 \\
\hline PAN & 152 & 245 & 203 & 600 & 111 & 67 & 422 \\
\hline PRD & 179 & 231 & 240 & 650 & 73 & 45 & 532 \\
\hline PRI & 205 & 226 & 226 & 657 & 88 & 91 & 478 \\
\hline Convergencia & 63 & 39 & 46 & 148 & 17 & 27 & 104 \\
\hline PVEM & 67 & 62 & 74 & 203 & 19 & 34 & 150 \\
\hline PT & 19 & 18 & 8 & 45 & 4 & 10 & 31 \\
\hline Nueva Alianza & 47 & 32 & 58 & 137 & 15 & 30 & 92 \\
\hline Alternativa & 15 & 19 & 18 & 52 & 2 & 5 & 45 \\
\hline Conjuntas & 16 & 27 & 40 & 83 & 29 & 3 & 51 \\
\hline Sin Partido & 2 & 1 & 17 & 20 & 0 & 0 & 20 \\
\hline Total & 849 & 963 & 1036 & 2848 & 426 & 321 & 2.106 \\
\hline
\end{tabular}

Fuente: Cámara de Diputados LX Legislatura en http:/ / sitl.diputados.gob.mx/estadisticas.html.

Cabe agregar que en diciembre de 2009 el Ejecutivo envió una iniciativa de reforma política al Senado que deja entrever varios objetivos de la elite panista. Estos objetivos van de asegurar la gobernabilidad, a través del aumento de facultades al Ejecutivo, y atender a algunas demandas de organizaciones ciudadanas y líderes de opinión pública encaminadas a controlar a los partidos y quitarles su monopolio de la representación. Las propuestas del Presidente, que hasta abril de 2010 se discutían, son las siguientes: reelección de legisladores y presidentes municipales, reducción de las cámaras de diputados y senadores, segunda vuelta para elegir presidente, aumentar el umbral para que un partido pueda mantener el registro (de $2 \%$ a $4 \%$ ), candidaturas independientes a todos los cargos de elección popular con 1\% de firmas del padrón electoral del distrito correspondiente; iniciativa ciudadana, iniciativa de la Suprema Corte para enviar propuestas de ley, iniciativa preferente del presidente, referéndum, veto parcial (podrá ser superado por $2 / 3$ partes de cualquier cámara) veto presidencial del presupuesto de egresos (parcial o total).

\section{RELACIÓN ENTRE PODERES}

Uno de los temas a discusión desde que se producen gobiernos divididos en México es el poco poder formal y de hecho que parece tener el Ejecutivo frente al Legislativo. 
Durante décadas, bajo el régimen de partido hegemónico, el Ejecutivo tenía un poder de hecho que le permitía dominar la Cámara de Diputados a través del PRI. En la medida en que la oposición creció y se institucionalizó el pluralismo se puso en evidencia el poco poder que tenía el Presidente frente al Legislativo. Se derrumbaron las tesis del "hiperpresidencialismo" y de la presidencia imperial. El último año de Fox fue paradigmático. En el contexto de la crisis desatada por la elección presidencial de 2006, miembros del PRD le impidieron a Fox entrar al recinto legislativo y entregar su último informe de gobierno. Según lo establece el artículo 69 de la Constitución en la apertura ordinaria del primer periodo de cada año de ejercicio del Congreso, el Presidente entregará un informe por escrito en el que manifieste el estado general que guarda la administración pública. Desde ese entonces, el Presidente no acude al Congreso de la Unión a presentar su informe anual.

Probablemente, uno de los temas más importantes a debate es el de la incertidumbre constitucional en torno al tema del presupuesto, lo cual explica la propuesta de Calderón en diciembre de 2009 de establecer el veto total o parcial del Ejecutivo en materia de presupuesto. Para autores como Carrillo y Lujambio (1998) el Ejecutivo en México es débil, cuando se analizan sus facultades en materia presupuestal. No tiene veto, ni total ni parcial, en esta materia. El Presidente formula el proyecto y lo envía a la Cámara de Diputados sin que pase a la Cámara de Senadores a revisión, pero no tiene capacidad para hacer observaciones al proyecto de ley que finalmente le remita el legislativo. Según estos autores, el Ejecutivo queda reducido a un mero funcionario técnico que hace los cálculos para que sea otra instancia la que tome las decisiones políticas y decida los rubros de la inversión pública. Hay que agregar que en el contexto de un Congreso poco profesionalizado, debido a que en México no existe reelección consecutiva de diputados, las consideraciones técnicas del Presidente pueden ser ignoradas.

Los poderes formales del Presidente son limitados aunque, en buena medida, la agenda parlamentaria es definida por el Ejecutivo.

\section{RELACIÓN ENTRE DISTINTOS NIVELES DE GOBIERNO}

No se registraron conflictos durante 2009 entre el Estado federal y los estados. No obstante, vale la pena mencionar que uno de los temas relevantes de 2009 fue, sin duda, la agenda que el PRD impulsó en el D.F., donde gobierna desde la democratización, logrando la despenalización del aborto (Avilés, 2009) y el reconocimiento de los matrimonios entre dos personas del mismo sexo (Editorial La Jornada, 2009). Se colocó como uno de los temas divisorios más importantes entre los partidos y la sociedad y entre los estados. La aprobación de leyes antiaborto en más de la mitad de los 32 estados de la República, promovidas por el PRI y apoyadas por el PAN, amenazó con convertirse en una ley federal y así revertir la medida en el D.F. (Jiménez, 2009).

El D.F. parece ser cada vez más una isla política y cultural de izquierda frente al conservadurismo que domina en la mayoría de los congresos locales. 


\section{EVALUACIÓN DEL FUNCIONAMIENTO Y CALIDAD DE LA DEMOCRACIA}

La evaluación de la calidad de la democracia siempre abre la interrogante acerca de los indicadores que deben ser tomados en cuenta. En México, como seguramente en otros países latinoamericanos, hay procesos traslapados y contradictorios en relación al funcionamiento y calidad de la democracia. Así, junto al avance que el país ha tenido en el ámbito de la competencia electoral, la institucionalización del sistema de partidos y la participación ciudadana se encuentran la erosión del Estado de derecho, cuyo indicador fundamental es la incapacidad del Estado para hacer vigentes los derechos humanos en algunas zonas del país y el fortalecimiento del crimen organizado que deteriora la calidad de vida de todos los ciudadanos. No es de extrañar que si tomamos en cuenta encuestas de opinión, la evaluación del público de la democracia mexicana es muy mala. De acuerdo al Informe Latinobarómetro (2009), en 2009 sólo 28\% de los mexicanos estaba satisfecho con la democracia.

Sin embargo, la narcoviolencia ha generado confusiones en el debate académico y político al punto de que es común leer y escuchar la tesis de que México aún no ha logrado establecer una democracia y que todos los avances de 2000 se fueron por la borda. Frente a ello, debe insistirse en que hay otros indicadores alentadores como el avance en materia de partidos, la relación de cooperación entre Ejecutivo y Legislativo y la percepción de una parte de las elites partidistas mexicanas de que debe impulsarse una reforma política que fortalezca la gobernabilidad, la rendición de cuentas, la participación ciudadana y una mayor representación. Justamente, con esta agenda política concluyó México el año 2009.

\section{REFERENCIAS}

Avilés Allende, Carlos. 2009. "Corte oficializa despenalización del aborto en el D.F.". El Universal [En línea] http:// www.eluniversal.com.mx/notas/580683.html [Consulta: 2-3-2009].

Cámara de Diputados. 2010. [En línea] http://sitl.diputados.gob.mx/estadisticas.html [Consulta: 2-42010].

Carrillo, Ulises. 1998. "La incertidumbre constitucional. Gobierno dividido y aprobación presupuestal en la LVII Legislatura del Congreso mexicano". Revista mexicana de Sociología 60 (2): 239-263.

Consulta Mitofsky. 2010. "Monitor mensual de Consulta Mitofsky. Economía, gobierno y política". [En línea] http://www.consultamitofsky.com [Consulta: 30-4-2010].

Delgado, Pamela. 2008. "El grupo parlamentario de Acción Nacional en la LX legislatura del Congreso de la Unión". El Cotidiano 23 (149): 73-81.

Economista (El). 2010. [En línea] http://eleconomista.com.mx/seguridad-pública/2010/04/13) [Consulta:13-4-2010].

Fernández Román, Emilio. 2010. “SME a huelga de hambre en el Zócalo". El Universal [En línea] http:/ / www.eluniversal.com.mx/notas/672308.html [Consulta: 12-4-2010].

Grajeda, Ella. 2009. "Asamblea legislativa aprueba uniones gay y adopciones". [En línea] http:/ /www. eluniversal.com.mx/primera/34131.html [Consulta: 22-12-2009].

Guerrero, Jaime. 2010. “Aprueban alianza PRD, PAN y PC, 'Unidos por la paz y el progreso'”. [En línea] htpp://e-consulta.com/Oaxaca [Consulta: 13-5-2010]. 
Instituto Federal Electoral. 2010. "Estadística electoral". [En línea] www.ife.org.mx [Consulta: 30-32010].

Jiménez, María Eugenia. 2009. “El aborto se castiga con prisión en 16 Estados". Milenio. [En línea] http:/ / impreso.milenio.com/node/8683604 [Consulta: 4-12-2009].

Latinobarómetro. 2009. "Informe Latinobarómetro". [En línea] www.latinobarometro.org.

Lombera, Manuel. 2009. “México no supo manejar la crisis: Stiglitz”. El Universal. [En línea] http:/ /www. eluniversal.com.mx/notas/640925.html, [Consulta: 19-11-2009].

Magaloni, Beatriz y Alejandro Moreno. 2010. “Captando todas las almas: el Partido Acción Nacional y la política de la religión en México". En La democracia cristiana en América Latina. Conflictos y competencia electora, editado por S. Mainwaring y T. Scully. México: Fondo de Cultura Económica, pp. 330-363.

Magar, Eric y Romero Vidal. 2008. "México: reforma pese a un gobierno dividido". Revista de Ciencia Política 28 (1): 265-285.

Martínez, Fabiola, Gustavo Castillo y Agustín Salgado. 2009. “Decreta Calderón la extinción de Luz y Fuerza: es inconstitucional: SME". La Jornada [En línea] http://www.jornada.unam.mx/2009/10/11/ index.php?section=politica\&article=005n1pol [Consulta: 11-10-2009].

México Unido contra la delincuencia. 2010. "Percepción ciudadana sobre la seguridad en México". [En línea] http://www.mucd.org.mx, [Consulta: 30-4-2010].

Palma Esperanza. 2009. “Abstencionismo y participación en las elecciones intermedias de 2009: problemas y desafíos de la consolidación democrática". En Los estados en el 2009: lucha política y competencia electoral, coordinado por G. López, R.M. Mirón y F. Reveles. México: Instituto Electoral del Estado de México/UNAM/AMCEE, pp. 57-71.

Roldán, Nayeli. 2010. "La 'huelga nacional' del SME queda reducida a puros mítines". Milenio [En línea] http://impreso.milenio.com/node/8734631 [Consulta: 14-3-2010].

Sánchez, Julián. 2009. "STPS niega toma de nota a sindicato electricista". [En línea] http:/ /www.eluniversal. com.mx/notas/631211.html El Universal [Consulta: 5-10-2009].

Secretaría del Trabajo y Previsión Social. 2009. [En línea] http:/ /gobiernofederal.gob.mx [Consulta: 135-2010].

Villalobos, Joaquín. 2010. “Doce mitos de la guerra contra el narco", Nexos 385: 24-29.

Esperanza Palma Doctora en Ciencias Políticas por la Universidad de Notre Dame, Estados Unidos.

Profesora Titular C del Departamento de Ciencias Sociales de la Universidad Autónoma MetropolitanaCuajimalpa, Ciudad de México. Coordinadora del Cuerpo Académico "Sociedad y Política".

Su principal línea de investigación es el papel contradictorio que juegan los partidos políticos en las democracias contemporáneas, en particular, las tensiones y ambivalencias en la estructuración de los sistemas de representación. 